\title{
Direct Payments for Older Adults in an Age of Austerity.
}

\section{Philippa Locke and Karen West}

Philippa Locke, School of Applied Social Science, University of Brighton, Mayfield House, Brighton BN1 9PH. p.locke@brighton.ac.uk (Corresponding Author)

Karen West, School of Languages and Social Science, Aston University, Birmingham, B4 7ET. k.west@aston.ac.uk

Philippa Locke is a Research Fellow in the School of Applied Social Science at University of Brighton. She completed her $\mathrm{PhD}$ "Exploring care relations in later life: disentangling notions of care and choice." at Aston University in 2016 and continues research into older people's experiences of care.

Karen West is a Reader in Sociology and Policy at Aston University, where she researchers and teaches on ageing, care and housing and work in later life. She is a leader of the Ageing Lives cluster in the Aston Research Centre for Healthy Ageing and a Visiting Professor at the University of Örebro. 


\title{
Direct Payments for Older Adults in an Age of Austerity.
}

\begin{abstract}
Direct payments are a form of personalisation in which service users take full control of the organisation and management of their own care. This is considered to be a method that maximises autonomy choice and control. This article sets out findings from a study commissioned in 2016 by a local authority (LA) in England to explore older people's views of direct payments (DPs) for social care. Semi-structured interviews were undertaken with older people who were in receipt of DPs as well as older people who were receiving managed care packages. At the beginning of the project discussion took place with LA staff to set out themes to be explored, however, after collecting data it became clear that some themes bore little relevance to the lived experiences of those receiving DPs. The commissioned research was intended to explore the views of older citizens, but what it found was a chasm between the LA and its older citizens in understandings of needs and the capacity of DPs to meet them that is possibly indicative of the state of social care in an age of austerity.
\end{abstract}

Key words: Adult Social Care, Older People, Direct Payments.

\section{Introduction}

Personalisation has been a core element of social care policy and practice in the UK for well over a decade now, and particularly so in England, where it has been regarded by both policy makers and user advocates as an important vehicle for delivering autonomy, choice and control to adult social care users (Needham 2011). Personalisation in England and the UK is also part of a broader European shift towards the substitution of state-funded care for 'cash and counselling' (Glendinning, 2010), which, in turn might also be said to be part of a general trend towards individualisation in social policy (Lewis, 2007), into which older people have also latterly been incorporated (Coole, 2012). At the same time, commentators have long expressed concerns that personalisation in general may not deliver the same autonomising outcomes for older adults as for younger adults (Glendinning 2008; Moran et al, 2012; Woolham et al, 2013) and that Direct Payments (DPs), a form of personalisation in which service users take full control of the organisation and management of their own care, may be less suited to older adults than managed budgets (Age UK, 2013), a form in which local authorities manage social care budgets on citizens' behalf. Nevertheless, government policy documents have made it clear that DPs are preferable to managed budgets as a means of maximizing autonomy choice and control (Routledge and Carr, 2013) and take up rates for DPs is one indicator of local authority adult social care performance. A survey published by the Health and Social Care Information Centre in 2014 noted that only around ten percent of older adult social care users had taken up DPs compared with twenty four percent of younger people with disabilities (HSCIC 2014). Questions about whether personalisation, in whatever form, can work for older people remain (Lloyd 2014). West and Needham (2017)have even suggested that frail older people have become the 'unexceptional exception' to personalisation, unexceptional in that they constitute the largest social care user group, but exceptional in that the support conditions required for achieving meaningful personalisation for them are unlikely to be obtained, particularly in the case of DPs and under conditions of austerity in which support is unlikely to be available. This echoes a more general concern on the part of social gerontologists that the position of frail older people is being rendered ever more precarious by care policy frameworks and discourses that conceal fundamental dependencies (Grenier, Lloyd and 
Phillipson 2017) and that generic discourses, like personalisation, which connote empowerment for all, serve to draw attention away from the circumstances of specific user groups, frail older adults in particular (West, 2013). These trends predate austerity, but austerity gives them renewed impetus.

In this paper we draw on data collected as part of a Local Authority-commissioned research project on older adults attitudes to DPs, carried out in the latter half of 2016 on older social care users' attitudes to, and experiences of, DPs and managed care budgets. This data, and our account of the local authority context in which it arose, provides a window on the current state of local policy and practice and user experience concerning personalisation in general and DPs in particular. We draw particular attention to the ethical issues that arise as a consequence of rolling out DPs, as a strong form of personalisation, in an austerity context.

The paper will first set out the context and aims of our study and our methods. We will then present the findings under the following thematic headings: managing DPs; choosing DPs; sticking with managed care and the potential for empowerment and the flexibility of DPs. We will then consider the implications of these findings for the ongoing debate about personalisation and, in particular, drawing out its ethical implications. Here we explore two sorts of ethical questions. First, in terms of the ways in which austerity amplifies the disparity between a policy that mandates choice and control and the restrictions on people's day to day ability to enact choice. Second, in terms of what we might call the meta-ethics of personalisation as a policy that endures despite its now well documented shortcomings, particularly in relation to older people.

\section{The Study and Context}

This paper sets out findings from a study commissioned in 2016 by a local authority (LA) in England to explore older people's views of direct payments (DPs) for social care. The motivation for the commissioning the study was threefold: 1) the LA's low ranking in the national league table of DP uptake among young and old social care users; 2) the particularly low uptake among those over 65 and in certain geographical areas; 3 ) a feeling that social workers were not as active in promoting DPs as the LA's management would like, and that there was, therefore, a need to gain direct access to 'citizens' voices'. The research was commissioned in order: to explore: older people's understanding of DPs; to gain a better understanding of the context in which older people did or did not opt for DPs; to test older citizens' awareness of the ways in which DPs could be deployed and, in particular, in meeting their 'unmet needs', a term used by the LA to refer to non basic needs. The LA was particularly keen for older people to be made aware of the potential for DPs to be used creatively to enhance general quality of life. The research was directed by the adult services commissioning department and, from the outset, there was a tension. On some occasions, members of the team indicated that the LA was in listening mode, even indicating an openness to discovering that DPs were not the right mode of personalization for their older citizens, some of whom may well prefer to remain on Managed Budgets. On other occasions, an agenda of managerial fine-tuning the implementation of extending DPs to all older citizens was more in evidence. For example, the roll out of a new form of payment was discussed, in which citizens would be given a debit card from which they could access money directly for specified purposes only. This was seen as a means of a) avoiding the need for a separate bank account, often a deterrent to DP uptake; and b) eliminate inappropriate spending at the outset. While there is no doubt that the LA commissioned the research in good faith, there is equally little doubt that, faced with mounting fiscal and policy pressures, the managerial impulse came to predominate over the listening impulse. In this mode, LA staff were apt to take 'autonomising potential' 
(Needham, 2011) of DPs for granted. We will return to this tension in the concluding sections. What we will discuss in the main body of paper is the experiences and insights of social care users, highlighting the stark disparity between the LA's emphasis of the liberating and creative potential of DPs, on the one hand, and the care recipients concerns over the sustainability of their current care arrangements, on the other hand.

\section{Methods}

Semi-structured interviews were undertaken with 24 older people who were in receipt of DPs as well as older people who were receiving managed care packages. The LA was interested in getting beyond social workers' accounts of the challenges of DPs and wanted more direct access to 'the voices of older people' themselves. Our sample focused on the older person receiving care. However, recruitment was extremely difficult and our response success rate was only around $10 \%$. We were provided, through a secure password protected connection, with the names and contact details of social care clients. We were told whether they did or did not receive DPs but were given no other information regarding their care requirements. This was challenging for the researcher and as the recruitment involved a telephone conversation prior to interview, that proved an important opportunity to gain as much information about the individual as possible. Understandably there were a high number of people with complex needs who were not able to participate. We were also given details of the ethnicity of the individual. The recruitment rate here was extremely low, particularly in the 'Pakistani' community as the older person often did not speak English. The LA's own profiling analysis indicated that DP uptake varies with age group (uptake being lowest among the older old) and by ethnic group (uptake being lowest among the white population and highest among Pakistani and Black African elders).

The main purpose of the overall research was to achieve a depth of understanding of DP uptake and non-uptake among citizens than had been possible hitherto and, to this end, semi-structured interviews were the chosen research methodology. However, it was felt that it would also be useful to gain some insight into the factors that might begin to explain ethnic and age group differences. So far as practicable, research participants would, therefore, be drawn from different age groups and ethnic backgrounds. However, low numbers of participants preclude saying anything meaningful about ethnicity in this paper. The research was granted ethical approval by the University's ethics committee and was also scrutinised by the LA's own research governance officer. Both authors were involved in data collection. The first author coded the interview transcriptions beginning with a coding framework that was drawn from the topic guide used in interviews. The first author then collated initial themes which were then developed through discussion between the two authors. The following section discusses the findings.

\section{Findings}

\section{Managing DPs}

In addition to seeking the views of older people towards DPs in general, the LA was interested in understanding why certain care recipients did not take up the option of DPs, in particular why there was a greater uptake amongst the oldest old than among the younger old. In line with other research (Woolham et al. 2016) we found that those that did take up DPs often had a family member who was available, and willing, to either support them in the management of the care arrangements or to take on the responsibility entirely. For the younger old, their children and other relatives were younger and had work commitments and/or were caring for their own families and so were not always able to take on a large supporting role for their parents. As one participant explained about his children: 
"They are working 5 days or 6 days but they look after me Sunday. Sunday, they come here." (Male: 73: Pakistani: No DP)

The son of an older woman with complex care needs explained how the care was divided within his family:

"It's my son who actually administers the account because I'm a carer and he pays me and he pays the care company, whatever hours they do. My son and my daughter, they both work, I don't have any brothers or sisters so it is all on me." (Son of female: 75-84: White: DP)

We found that for the very old and those with significant impairments, such as dementia, were more likely to have their DPs fully managed by a family member. The younger old, those with stable disabilities and a supportive partner or family were more likely to manage the DPs themselves. The option to take DPs appears to be more feasible if there is someone willing to support the older person in managing the process.

The LA was concerned that the administrative burden of becoming an employer would be off-putting for older people and so it encouraged the use of external organisations -direct payment support service providers - that provided payroll management services. Those managing the DP provided the names and details of carers and hours worked and the payroll was calculated by the support provider.

In our research all the participants used one particular support provider and were happy with the service they received. They reported the process of recording carers' hours as fairly straightforward and unproblematic process. However, questions arose around other areas of employment law:

“There's just certain information that I didn't understand because they don't pay sick pay so if they [carers] are ill they won't pay towards that. They said that they can have holidays but there's no money for holiday pay so what we've been doing is just paying them and then I've just done when they're off." (Daughter of female;75-84; Black-African Caribbean)

For some this led to a struggle with their own ethical position as in addition to not being supported in paying sick pay or holiday pay they had little flexibility over rates of pay.

The LA took the view that the challenge of becoming an employer would be related to compliance with employment law and so ensured that there were organisations available to provide payroll and taxation management services. All of the participants who were receiving DPs used this services but still had difficulty with certain aspects of becoming an employer. For example, there were concerns over changes to employment law and participants expressed concerns regarding the impact of future changes to pension contribution rules. One participant described how the pension changes were already impacting on their costs because of the need to pay the payroll service for calculating their liability:

"They charge $£ 5$ per carer, per quarter, so the more carers you have the more it costs. It's just cost me $£ 60$ odd pounds because the government's just decided that we've got to pay for pension contributions. None of them earn enough to even think about it because you've got to earn $£ 190$ or $£ 180$ per week ... but the Direct Payment Support Service have still had to 
charge me for doing all the paperwork and registering an employee to deal with the pensions." (Male: 71: White: DP)

The participants appreciated and valued the work that their carers did and the support that they provided and wanted to offer a rate of pay that reflected that value. They were also concerned about keeping good carers because of the work involved in finding and adjusting to new carers:

“... I pay more than the minimum pay if I don't pay the carers they're going to say well we can get a better job somewhere else. And it takes a while to get carers, we've been lucky but we've also been unlucky in some ways because we've had people start off that we thought were alright and they haven't been alright." (Male: 71: White: DP)

The choice to pay carers above the prescribed amount was only available to individuals who had personal financial resources to draw on. Others were unable to make any payments other than those set out in their care assessment.

We found that most participants on DPs were required to make some contribution to their care and that the contribution is regularly increased. One participant described how this contribution had changed over recent years and how this is a serious cause for concern for him:

"I've been on the direct payment for 8 years now, right, the payment has never gone up. Wages and everything else has gone up ... I'm now paying about $60 \%$ of my care because each year the government has taken a bit more off so I'm having to pay more and more. When I first went on to it I was paying nothing, now I'm paying $60 \%$ so in another 5 years' time I might be a 100\%.“(Male: 71: White: DP)

The concern over the increase in the contribution they were required to make was mentioned by all the participants in receipt of DPs. It is clear that although their care needs have not been reassessed, the LA is likely to be making significant savings by not having to meet the increased costs of care whilst still meeting their obligation to provide some financial support.

The difficulties that the participants had in relation to DPs were not associated with the payroll administration but rather with the principles behind the funding of care which does not include allowances to cover carers' sick leave or holiday pay. Several participants also made it clear that they make contributions towards their care. The reducing contribution of the LA can be attributed to the ongoing cuts that all LAs have been required to make because of austerity measures. The LA is also cutting costs through the transfer of the management of payroll systems from their control to individuals and local support services providers.

\section{Choosing DPs}

For most of the participants who had moved to DPs from a LA managed care package, the choice was a reflection of the difficulty they had with the timing of visits, constantly changing care staff and lack of control that they felt they had over their care. 
"There's times when my mum doesn't want to get up early so if we have flexible carers who can come at different times it helps then. Whereas if they had, if we didn't have the direct payment and the NHS was coming or whoever else was coming they'd have to come at the set times and then it's no help really then is it?" (Female: 82: Black African Caribbean: DP)

The difficulty with the lack of control under a managed care package was also described by a husband and wife who had moved to DPs. Arthur (had a spinal injury and his wife, Donna, had limited use of her right arm), whilst Arthur received DPs, Donna's needs were not assessed as qualifying for services. They had moved over to DPs many years ago:

"I sort my own carers out because the carers that was coming in were coming in at all peculiar hours, coming in to put me to bed at 5 o'clock of an evening ... one of the things they were supposed to do was change Donna's bed once a week because Donna can't do it. And when we asked the carer to do it she absolutely refused and walked out. .... when you're with the council see, you're lucky if you got the same person twice in one week." (Male: 71: White: DP)

Several participants employed their adult children as carers. Whilst this provided the individual with care that was comfortable and reliable, those children have to take on outside jobs to supplement the payments they receive. One participant's daughter was working two cleaning jobs that she fitted around the care of her mother and another described how employing her daughter changed her care routine:

"...it's my daughter, when it used to be civil care, it used to be two carers because the female lady was for me and the male was for my husband so we had two carers come in in the morning ... Since my daughter take over its only just she alone. So she comes in in the morning and looks after me and my husband and after she came in she had to go to other jobs so she comes back between one and two o'clock and she gives him his afternoon tablets." (Wife of male: 65-74: Black-African Caribbean)

Not all older people have the option of employing a family member as a carer and in these cases the choice to move over to DPs is the start of a series of decisions.

Making a choice about care providers is one step in a process as it is only once the care relationship is in place is it possible to determine whether or not a 'good' choice has been made.

"... they would come in the morning, dress me on the bed. Hoist me up and take me down stairs ... there was so many different carers, I got to know most of them but sometimes they'd come in, I'd hear them coming up the stairs arguing about or discussing some upset in the office and all that kind of thing. They'd come in and start doing this and doing that for me, talking across me. I was just a piece of meat." (Male: 75: White: DP)

Our participants reported that recruiting carers from private care agencies did not guarantee good care and a process of trial and error was needed when recruiting private carers, both through agencies and as individuals. Reports of poor care highlights the vulnerability of those who require care in their home: 
"Sometimes my mum has a little accident with urine in the bed, but they're not checking the bed. Making the bed and it was still wet underneath, instead of clearing the bed and I'm thinking well you've seen my mum, you've got her ready, she's clearly wet, haven't you checked the bed?" (Female: 82: Black African Caribbean: DP)

In addition to poor care a missed visit can lead to individuals being left in distress.

"One weekend my mum was, as I say she's vulnerable moving around the flat and she needs help to be put to bed now and one Sunday night they didn't turn up at all. I came in the next day, my mum was on the settee for the whole night. I said what's going on here, you know, basically the girl who runs the company was under the understanding that someone was going to go and again, you know, a breakdown in communication and no one came. It's been pretty daunting and it's been a struggle." (Female: 7584: White: DP)

DPs were seen as successful by the participants because they were able to change carers or care companies, but this was a big step and would only be considered when the LA-arranged care received was not appropriate or was deemed no longer acceptable. The risks and challenges faced by all employers in the care industry - difficulty in recruiting cares , covering sick and holiday leave, maintaining quality of care -are transferred from the LA to the individual. The cost of managing these tasks is also reduced for the LA allowing it to reduce its own administrative costs and, as we noted above, in the severely straightened financial circumstances of the LA, recipients are being asked to contribute more of their own resources to the cost of their care.

\section{Sticking with managed care}

Whilst poorly managed care was a motivator for some to move to DPs, for others the early stages of dementia meant that the direct employment of carers was beyond their capabilities. However, for some older people the managed care they received seemed to meet their needs. One participant in our study was adamant she wanted to stay on a managed budget as, in her view, she had a great relationship with her carers and was scared that she would lose them. This was an important relationship that she felt was threatened by the introduction of DPs. Although she was mentally competent and would be able to manage DPs and could possibly have retained the same carers, there was no need to take on the burden of managing finances and employment law when her current situation suited her very well.

Marie had complex health issues and was already having to manage her travel arrangements as well as the daily challenges of living with her disability. She is very happy with her current care team, they are reliable, flexible and attentive:

"I get help four times a day. My dialysis is Monday, Wednesday, Friday and I get care then twice a day. But, you know, they'll do anything for me ... I can't wish for a better team than what I've got. I mean they'll even come back if I'm late from the hospital they'll come back when I'm ready to come home." (Female: 68: White: No DP)

Marie's carers are happy to change the timing of her visits on a day to day basis. Despite being on a managed care package Marie still felt that she had some choice over the company that provided her care. She explained that she had been with a different care company 
before but when her health declined and she could no longer transfer herself out of her wheelchair she changed to a company that trained their carers to use hoists. She was extremely loathe to jeopardise the arrangements that had taken a lot of patience and effort to fine-tune.

Marie was very happy with her current carers and stated several times that her carers "would do anything for me." She was concerned that she would be expected to move to DPs and that not only would that disrupt her current care arrangements but she was also concerned about managing the payments. Marie does do some telephone banking but her contributions towards her care are made through the post office with the help of a friend:

"I can't get to the post office or the bank because of the way I am so my friend next door she takes it for me and if she has a lot of money she won't take it... she's scared of getting hit on the head or whatever and then it robbed off her." (Female: 68: White: No DP)

In contrast to other situations where problems with care were a motivation to move to DPs Marie's situation showed that there will always be older people whose daily lives are already so challenging that the additional responsibilities of care management would simply be too much.

\section{The Potential for Empowerment and the Flexibility of DPs}

At the beginning of the project discussion took place with LA staff to set out themes to be explored, however, after collecting data it became clear that some themes bore little relevance to the lived experiences of those receiving DPs. For example, the LA wanted to explore whether citizens would be interested in pooling their DPs - meaning to get together to fund a group activity to gain greater benefit. However, many DP recipients were making contributions to their payments to simply cover the cost of day to day personal care needs, leaving no surplus funds for other uses. Another question was whether citizens would be interested in being involved in a citizen-led support network for DP recipients. When questioned on this, participants felt that were fully occupied with managing their own care needs and had neither the time nor the resources to expand their current support networks or had such complex needs that they required additional support themselves. For the most part, annual reviews of DPs were undertaken by phone and a consequent lack of face to face contact between those who are managing DPs and the LA contributes perhaps also contributes to this lack of understanding of the challenges that caring for older people entails.

Again, in order to promote the more creative use of DPs, the LA wanted to determine whether citizens understood that they could spend their DP on anything which could be linked back to their support plan. When participants in this study were asked about whether they were aware that they were able to use their DPs to for these so-called 'unmet needs' they were often confused by the question.

All participants were required to make a contribution to their care which meant that the DP they receive did not cover the full amount of their care. For this reason the questions about using excess funds to address unmet needs or to pool/share with others seems completely alien to the issues at hand. Similarly, the much vaunted flexibility and autonomising potential of DPs needs to be set against the increased challenges and risks that are associated with employing carers that are faced by all those in the care sector: difficulty in recruiting carers, difficulty in retaining carers, low pay, no sick pay, no holiday pay. 


\section{Discussion}

In this section we want to draw out the broader ethical implications of our findings. These we want to argue are on two levels: First, the personalisation agenda in general raises wellrehearsed ethical questions regarding the limits of choice and, DPs, as a strong form of personalisation, raises further questions about the ethics of mandating the self-management of care arrangements among older adults who may lack the capacity, support networks or desire to take this on. On a second, what we might call, meta-ethical level, there are questions about the way in which LA commissioners, under conditions of austerity, seek to manage conflicts between caring for older citizens and harsh financial realities.

\section{The ethics of choice and self-management}

The ethical conflict at the heart of personalisation has long been recognized. For example, Waerness (2001) noted that the providers' focus is on the economics of care provision, which is in conflict with a relational perspective on care. Lloyd makes the same point a decade later in the context of personalization (Lloyd 2010) and Fine (2013) notes that 'tailor-made finance' is not the same as 'tailor-made-care'. The needs of vulnerable older can be complex and significant, yet DPs are typically seen through the lens of empowerment by 'exit' and 'voice' (Vamstad 2015). Among our participants, the 'choice' for moving to a DP was often made because of the deficiencies of care provided through managed care packages, either because the timing of visits was not suitable or because there was insufficient continuity or quality of care. Choice in this context is more about the avoidance of continued harm than about empowerment (Vamstad, 2015) through voice or exit. The participants in this study were 'necessarily dependent' (Lloyd 2010) and did not have the option of making no choice or of choosing not to receive care. Moving to a DP was for some the only alternative to managed care. On the other hand, others were reluctant to move to DPs from a managed care budget for fear of disrupting the care arrangements that had taken time and effort to fine-tune. These are often not perfect, but the risk of complete disruption may be too great to countenance. The time consuming nature of establishing decent care arrangements (Baxter, Glendinning and Clarke 2008) which may hang by a thread, is a barrier to exit and voice.

On the question of the higher level of self-management that conversion to a DP implies, the LA understood that this was a potential barrier for older service users. However, this was understood purely in terms of the increased complexity of managing the legal requirements of employers, whereas for participants, there were ethical issues involved in having no choice but to under pay care stuff or in knowingly not allowing for sick pay or holiday pay. As suggested by Hussein and Manthorpe (2014) the issue of low pay for direct care work has been neglected in discussions of cash for care. Where participants had the personal means they would pay above the recommended rates in recognition of the value they placed on the care they received.

It is important to also keep in mind that some people choose to have a managed budget because they have no need for greater choice and control than they already have. As Orellana (2010) and Glendinning et al. (2008) have argued some older people do not want to change or transform their lives to become empowered, independent citizens. The participant on a managed package discussed in the findings was certainly concerned that there was an expectation that she would move to DPs. This echoes Owens, Mladenov, and Cribb's $(2017,12)$ concerns that "constructing the autonomous and empowered service user as the manager of a personal budget will exclude those who either cannot or will not take on this role, and in so doing fail to respect and respond to other forms of autonomous expression". 


\section{The meta ethics of personalization and austerity}

As noted in the introduction, the LA which commissioned this research faced a number of pressures. On the one hand, the pressure to move more of its older citizens onto DPs and away from managed budgets. Part of what it wanted to achieve was a better sense of the difficulties older citizens already on DPs were experiencing and how these might be addressed. It also wanted to explore ways in which citizens could use DPs more creatively, either by pooling budgets with other users or of using them for 'unmet needs'. In practice, there was a gap (previously noted by others, e.g. Lloyd 2010) between these aspirations and the day-to-day reality of the participants we interviewed, a gap that has widened in part because of the withdrawal of meaningful social worker intervention. The LA did not appreciate that the funding that was provided was not sufficient to cover the cost of basic care, although previous research has shown that it is a common practice to allocate the minimum, or less than the minimum, level of funding to meet actual needs (O'Rourke, 2016). In one notable case, rules about DP spend additionally precluded the purchase of new toilet seat to replace an old cracked and dangerous one. The review of DPs by social workers seemed to be little more than a financial assessment and, often conducted over the phone, if at all.

It has been suggested that debates surrounding the personalization of care are shifting from concerns about individual choice and responsibility towards a greater awareness of the role of trusted and meaningful relationships (Glasby and Needham 2014:1990). There were vestiges of such a discourse in the LA's espoused openness to learn from the voices of citizens and their everyday experiences and to even entertain the idea that managed budgets may be better for some in certain circumstances. There were vestiges of this too in the sincerely espoused idea that older citizens were missing out on the autonomising and empowering potential of DPs, which, it was felt, social workers may not be explaining carefully enough. In the final analysis, though, this listening impulse gave way to a more managerial impulse when the harsh day to day realities of vulnerable citizens fashioning care from restricted resources, with a set of rules that were often hard to comprehend and often with limited support from families and wholly inadequate support from over stretched social workers, clearly ruled out that potential. In such circumstances, a discourse of personalization as self-evidently a good thing and, therefore, to be rolled out regardless, became more evident. Although the research was motivated in part by concern about the LA's low conversion rate and a feeling that evidence from users may bolster the resistence, when commissioners of adult social care are powerless to alter the financial circumstances of care, circumstances that are wholly inconducive to caring, meeting targets is perhaps a more comfortable objective.

\section{Conclusion}

The evidence we have presented in this paper is limited by the size of our sample. Nevertheless, the experiences of older social care users we have presented reinforces longstanding concerns about the personalization agenda and the more recent policy of bolstering the uptake of DPs, a particularly strong form of personalization. We found that DPs were more likely to be taken up by older people who had families who were able to employ carers on their behalf. We also noted how DPs raise a variety of ethical issues, including the simultaneous addition of the burden of taking on an employment role and the subtraction of any capacity to appropriately value the care received. These will hardly be new to those who have studied the development of social care over the last decade or so. Indeed, we felt ambivalent about taking on the research when so much is already known about the corrosive effects of this particular form of personalisation. What motivated us, however, was the apparent early willingness of LA commissioners to review recipients' experiences openly. 
The fact that, in the final analysis, they were unable to take on board these key messages and, instead, pursued a well-trodden path of managerial implementation, leads us to consider again the meta-ethics of personalisation. The commissioned research was intended to explore the views of older citizens, but what it found was a chasm between the LA and its older citizens in understandings of needs and the capacity of DPs to meet them that is possibly indicative of the state of social care in an age of austerity. In the final analysis, 'personalisation' continues to fulfil its purpose, as we have argued before as a useful way of managing waning social care resources.

\section{References}

Age, U.K., 2013. Improving later life. Understanding the oldest old. London: Age UK. Baxter, K., Glendinning, C. and Clarke, S., 2008. Making informed choices in social care: The importance of accessible information. Health and Social Care in the Community, 16(2), pp.197-207

Coole, D. (2012) 'Reconstructing the elderly. A critical analysis of pensions and population policies in an era of demographic ageing', Contemporary Political Theory, vol 11, pp. 4167.

Fine, M. D., (2013) Individualising care. The transformation of personal support in old age. Ageing and Society, 33(03), pp421-436

Glasby, J. and Needham, C., 2014. Glass half full or glass half empty. In C. Nicholson and J. Glasby, eds. Debates in Personalisation. Bristol: Policy Press, pp. 185-191.

Glendinning, C. (2010) 'Continuous and long-term care: European perspectives', in Dannefer, D. and Phillipson, C. The Sage Handbook of Social Gerontology

Glendinning, C., Challis, D., Fernandez, J.-L., Jacobs, S., Jones, K., Knapp, M., Manthorpe, J., Moran, N., Netten, A., Stevens, M. and Wilberforce, M. (2008), "Evaluation of the individual budgets pilot programme: final report", Social Policy Research Unit, University of York, York

Grenier, A., Lloyd, L. and Phillipson, C. (2017) 'Precarity in later life. Rethinking dementia as a 'frailed' old age'. Sociology of Health and Illness, vol 39/2, pp. 318-330.

HSCIC (Health and Social Care Information Centre) Community Care Statistics, Social Services Activity, England, 2013-2014, (2014) Final Release. http://www.hscic.gov.uk/catalogue/PUB16133/comm-care-stat-act-eng-2013-14-fin-rep.pdf (accessed 24 April 2016).

Hussein, S, and Manthorpe, J. 2014. "Structural Marginalisation among the Long-Term Care Workforce in England: Evidence from Mixed-Effect Models of National Pay Data." Ageing and Society 34 (1). Cambridge University Press: 21-41. doi:10.1017/S0144686X12000785.

Lewis, J. (2007). Gender, ageing and the "new social settlement": The importance of developing a holistic approach to care policies. Current Sociology, 55(2), 271-286. https://doi.org/10.1177/0011392107073314 
Lloyd, L. (2010). "The Individual in Social Care: The Ethics of Care and the 'Personalisation Agenda' in Services for Older People in England." Ethics and Social Welfare 4 (2): 188-200. doi:10.1080/17496535.2010.484262.

Lloyd, L. (2014), "Can personalisation work for older people", in Needham, C. and Glasby, J. (Eds), Debates in Personalisation, Policy Press, Bristol, pp. 57-66.

Moran, N., Glendinning, C., Wilberforce, M. Stevens, M., Netten, A., Manthorpe, J., Knapp, M. Fernandez, J.-L., Challis, D. and Jacobs, S. (2012), Older people's experiences of cashfor care schemes; evidence from the English individual budget pilot projects. Ageing and Society, 33, 5, pp. 826-851.

Needham, C. (2011), Personalising Public Services: Understanding the Personalisation Narrative, Policy Press, Bristol.

Orellana, K. (2010). Personalisation in practice: lessons from experience. Making Personal Budgets, Support Planning and Brokerage Work for People in Later Life. Age UK, London.

O'Rourke, G. (2016) Older People, Personalisation and Self: an alternative to the consumerist paradigm in social care. Ageing \& Society, 36(5), pp. 1008-1030. doi: $10.1017 / \mathrm{S} 0144686 \mathrm{X} 15000124$.

Owens, John, Mladenov,T. and Cribb, A. 2017. "What Justice, What Autonomy? The Ethical Constraints upon Personalisation." Ethics and Social Welfare 11 (1). Taylor \& Francis: 3-18. doi:10.1080/17496535.2016.1234631.

Routledge, M. and Carr, S. (2013), Improving Personal Budgets For Older People: A Review, TLAP and SCIE, London.

Vamstad, J. 2015. "Exit, Voice and Indifference - Older People as Consumers of Swedish Home Care Services." Ageing and Society, no. Available on CJO 2015: doi:10.1017/S0144686X15000987. doi:10.1017/S0144686X15000987.

Waerness, K. (2001) 'Social Research, Political Theory and the Ethics of Care', Research Review, Vol. NS 17, no. 1, pp. 5/16.

West, K. (2013), “"The grip of personalisation in adult social care. Between managerial domination and fantasy"”, Critical Social Policy, Vols 33/4, pp. 638-657.

West, K. and Needham, C. (2017) 'Making it Real or sustaining a fantasy? Personal Budgets for Older People', International Journal of Sociology and Social Policy, vol 37/11-12, pp. 683-695.

Woolham, J. and Benton, C. (2013), The costs and benefits of personal budgets for older people: evidence from a single local authority. British Journal of Social Work, 43(8), 14721491.

Woolham, J., Daly, G., Sparks, T., Ritters, K., and Steils, N. 2016. "Do Direct Payments Improve Outcomes for Older People Who Receive Social Care? Differences in Outcome between People Aged 75+ Who Have a Managed Personal Budget or a Direct Payment." Ageing and Society, 1-24. doi:10.1017/S0144686X15001531. 